\title{
A escolha da carreira docente em Física: tensões e desafios ${ }^{+*}$
}

\author{
Marta Fernandes Garcia ${ }^{1}$ \\ Instituto Federal de Educação, Ciência e Tecnologia de São Paulo \\ Campus Cubatão \\ Maria Cláudia Silva Batista ${ }^{2}$ \\ Graduanda do curso de Licenciatura em Física - IFSP \\ Campus Registro \\ Dirceu da Silva ${ }^{3}$ \\ Faculdade de Educação \\ Universidade Estadual de Campinas \\ Campinas - SP
}

\section{Resumo}

$O$ artigo analisa aspectos relacionados com a escolha da carreira docente em Física por estudantes de um Instituto Federal de Educação, Ciência e Tecnologia de São Paulo. Para a coleta de dados, foram aplicados 4 questionários com os objetivos de (1) delinear o perfil dos estudantes; (2) compreender as razões e influências na escolha do curso de Licenciatura em Física; (3) analisar as marcas na trajetória escolar que colaboraram para esta escolha e (4) identificar, na visão dos estudantes, as experiências de formação que têm contribuído para despertar/aumentar o desejo pela carreira docente em Física. Os dados foram submetidos à análise categorial temática. Os resultados evidenciam, entre outros, que a localização próxima à residência dos alunos e a escassez de cursos gratuitos na região têm forte relação com a escolha do curso. Menos da metade dos estudantes apontou ter escolhido o curso em decorrência da identificação com a Física e do desejo de lecionar. Ainda, um pouco mais da metade afirmou ter recebido algum tipo de in-

\footnotetext{
${ }^{+}$The choice of the teaching career in Physics: tensions and challenges

* Recebido: abril de 2017.

Aceito: novembro de 2017.

${ }^{1}$ E-mail: martagarcia@ifsp.edu.br; ${ }^{2}$ E-mail: mariaclaudiasilvabatista@gmail.com;

3 E-mail: dirceu@unicamp.br
} 
fluência na escolha do curso e demonstrou o desejo de lecionar após se formar.

Palavras-chave: Formação de professor; Física; Carreira docente.

\begin{abstract}
This article analyzes aspects related to the choice of teaching Physics as a career by students of a Federal Institute of Education, Science and Technology of São Paulo. For the data collection, 4 questionnaires were applied to (1) outline the profile of the students; (2) understand the reasons and influences in the choice of the Licentiate degree in Physics; (3) analyze the main events in their school trajectory that contributed to this choice and (4) identify, in their perspective of the students, the training experiences that awakened / increased the desire for a teaching career in Physics. The outcomes reveal that proximity to the student's home and the lack of free degrees in the region, among other factors, are strongly related to the choice of their careers. Less than half of the students indicated that they chose the program due to identification with Physics and due to their desire to teach. Moreover, a little more than half of the students stated they received some type of influence in the choice of the course and intend to teach after graduating.
\end{abstract}

Keywords: Teacher training; Physical; Teaching career.

\title{
I. Introdução
}

A literatura tem ressaltado (NOGUEIRA, 2010; VIEIRA, 2014; PINTO, 2014; RABELO; CAVENAGHI, 2016) e os dados evidenciado que as carreiras voltadas para o magistério na educação básica são cada vez menos procuradas entre os jovens em decorrência do baixo retorno econômico e simbólico. Recentemente, a Folha de São Paulo divulgou uma matéria com o título: "Nenhum jovem quer virar professor no Brasil, mostra exame da OCDE 2 ", apontando que o número de alunos brasileiros de 15 anos que declararam interesse pela docência foi zero. Dado alarmante que reforça a necessidade de reflexão e discussão sobre os encaminhamentos e políticas educacionais de formação inicial e continuada de professores e de valorização do magistério.

\footnotetext{
2 A notícia foi divulgada em 07/12/16. Pode-se consultar a matéria completa em: <http://www1.folha. uol.com.br/colunas/ericafraga/2016/12/1839126-nenhum-jovem-quer-se-tornar-professor-no-brasil.shtml>.
} 
Segundo Rabelo e Cavenaghi (2016), o governo federal tem realizado algumas ações diante da escassez e fragilidade da formação docente, sendo uma delas a criação, em 2008, dos Institutos Federais que destinam, no mínimo, 20\% de suas vagas para cursos de licenciatura, sobretudo nas áreas de ciências e matemática. No entanto, as próprias autoras esclarecem que esse acréscimo do número de vagas em cursos de formação de professores sofre os efeitos da baixa taxa de conclusão, do aumento do tempo de finalização dos cursos e da baixa permanência de docentes nos cursos de Física, Matemática, Química e Biologia.

Ainda, a pesquisa de Rabelo e Cavenaghi (2016) revela que apenas 26,8\% do total de professores de Física possuem formação adequada para ministrar esta disciplina e que as taxas de conclusão dos cursos de licenciatura são baixíssimas: considerando os ingressantes do ano de 2009, somente 20,5\% concluíram o curso de Física. Em tempos de debate sobre a reforma do ensino médio, não podemos nos esquecer de que a qualidade do ensino passa também pela disponibilidade de profissionais com formação adequada. Além disso, políticas públicas educacionais precisam garantir melhorias na carreira docente, tornando-a mais atrativa no que se refere à valorização do professor, às condições de trabalho e desenvolvimento profissional. Isto porque é insuficiente ter professores bem formados se eles não desejarem exercer sua função em sala de aula.

Louzano et al. (2010) esclarecem que, no Brasil, a queda na demanda pelas licenciaturas e no número de formandos, bem como a mudança de representação do público, no qual geralmente são atraídos alunos com baixo rendimento acadêmico e com perfil socioeconômico inferior para cursos voltados à formação de professores, é o retrato atual da atividade docente no país. Assim, frente à significativa dificuldade de oferta adequada de docentes para atendimento do sistema de ensino brasileiro nas disciplinas de Física, este artigo pretende contribuir com reflexões acerca dos motivos relacionados com o processo de escolha da carreira docente por estudantes de Licenciatura em Física do Instituto Federal de Educação, Ciência e Tecnologia do Estado de São Paulo, campus Registro, bem como problematizar as experiências de formação na graduação que contribuíram, na visão dos estudantes, para despertar ou aumentar o desejo pela carreira docente em Física.

\section{A formação de professores no Brasil: reflexões sobre dados expressivos}

A qualidade da formação de professores é um tema relevante e sempre presente nas pesquisas da área da educação e, por vezes, se constitui em temática de discurso político quando da intenção de criação ou reformulação de políticas públicas educacionais. No entanto, quando se constata a realidade brasileira sobre a baixa procura pela profissão docente, questões como trabalho, carreira e desenvolvimento profissional se tornam fundamentais e necessitam de reflexão e encaminhamentos, uma vez que estão relacionadas com a qualidade da educação. Mudanças na política educacional que não alteram o quadro dramático das condições de trabalho, salário e carreira e que não investem na formação do futuro professor certamente não terão bons resultados. Sabemos que a equação da qualidade do ensino envolve 
formação, condições de trabalho, salário e carreira. Ainda, destacamos que a dimensão da formação necessita abranger, além das questões curriculares, as características socioeducacionais e culturais dos estudantes, aspectos também relacionados com a permanência e evasão nos cursos.

Gatti (2014) realizou uma síntese do estado do conhecimento sobre formação inicial de professores nos cursos de graduação e apontou aspectos que são recorrentes em pesquisas educacionais, o que significa dizer que há problemas históricos ainda não solucionados. Dois deles interessam diretamente a este trabalho: número de professores improvisados e características socioeducacionais e culturais dos estudantes dos cursos de licenciatura. O primeiro revela o alto grau de carência de professores com formação adequada na área em que atuam, especialmente, em Física. De acordo com a autora, as pesquisas analisadas em sua investigação atestam o fato de que o número de matrículas em cursos de Física, Matemática e Química vem caindo ao longo dos anos e que a não conclusão dos cursos gira em torno de $70 \%$.

O segundo problema aponta que sem a devida atenção às necessidades dos estudantes, perde-se a oportunidade de uma boa formação, capaz de fascinar e envolver os alunos e de reverberar em práticas desejáveis na educação básica, respaldadas em conhecimentos específicos e pedagógicos sólidos. Além disso, a atenção ao estudante pode contribuir para a sua permanência adequada no curso. Por esta razão, é válido atentar para os dados enfatizados por Gatti (2014) provenientes dos questionários do Exame Nacional de Desempenho de Estudantes (ENADE) sobre o perfil dos estudantes de licenciaturas: $39 \%$ com renda familiar de até 3 salários mínimos; $51 \%$ estão na faixa de renda familiar entre 3 a 10 salários mínimos, com aproximação maior do limite inferior; apenas $2 \%$ não trabalham e são inteiramente custeados pela família; $9 \%$ possuem pais sem instrução e, somando-se esses aos que têm pais com até o $4^{\circ}$ ano do ensino fundamental, chega-se a quase metade dos alunos; $46 \%$ dos estudantes estão na faixa etária ideal (de 18 a 24 anos) e a grande maioria é proveniente de escolas públicas. Uma vez conhecendo o perfil dos alunos, acreditamos ser fundamental pensar ações pedagógicas e institucionais de formação e acolhimento.

A pesquisa de Oliveira et al (2011) investigou 60 alunos do terceiro ano do ensino médio do Estado de Minas Gerais provenientes de duas escolas, sendo uma pública e uma privada. Diante da indagação: "você seria professor?", apenas $23 \%$ afirmaram que sim. Ainda, do total de alunos investigados, $42 \%$ informou que seria professor somente se a profissão fosse melhor remunerada e $10 \%$ se fosse mais valorizada pela sociedade.

Kussuda (2012), por sua vez, analisou a escolha profissional de egressos do curso de licenciatura em Física da UNESP de Bauru nas duas últimas décadas. Dos 52 licenciados que participaram do estudo, 40 ingressaram no magistério após a conclusão do curso, sendo 7 deles exclusivamente no ensino superior. Já os dados sobre evasão mostraram que dos 40 licenciados que atuavam no magistério, 13 abandonaram a carreira, sendo 10 provenientes da educação básica. Uma das conclusões do autor é que a carência de professores dessa área não se dá apenas em função do número reduzido de formados, mas é agravada fortemente pela saída 
desses da área da educação em função da insatisfação com os salários, com as condições de trabalho na educação básica e da dificuldade em desenvolver o conhecimento acumulado na universidade na prática docente nas escolas. Este último elemento aponta para a necessidade de desenvolvimento da formação pedagógica do futuro professor, uma vez que os saberes pedagógicos são estruturantes da profissão e são provenientes tanto da formação docente inicial quanto do próprio exercício da docência.

Os dados a seguir ilustram os estudos e dados apresentados neste trabalho.

Gráfico 1 - Proporção de docentes que possuem formação superior compatível com a área de conhecimento que lecionam - Ensino Médio. Brasil, 2016.

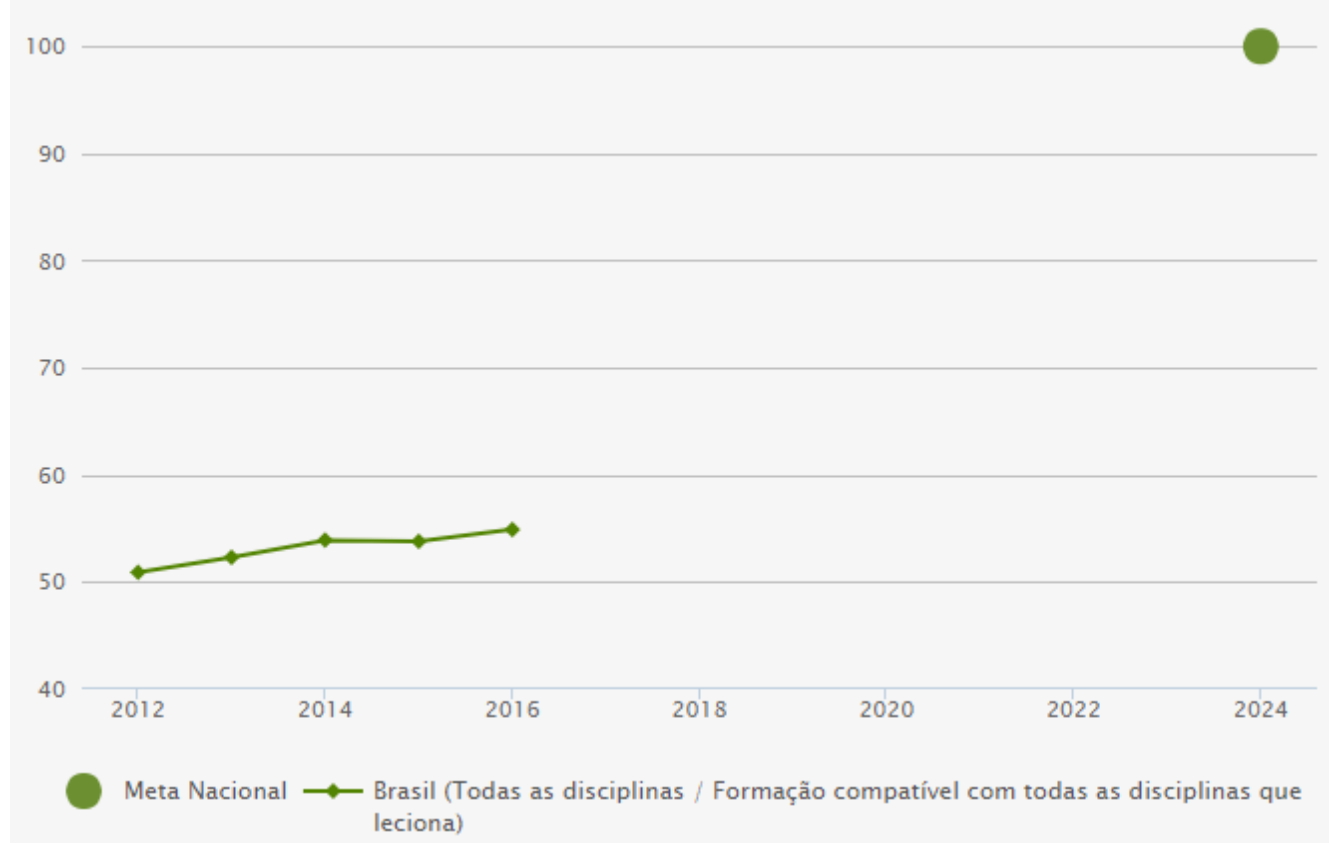

Fonte: Observatório do PNE.

A meta 15 do Plano Nacional de Educação (PNE), em vigor desde 2014, determina que todos os professores da educação básica devem possuir formação específica em nível superior na área de conhecimento em que atuam até 2024. O gráfico 1 mostra que no ano de 2016 a porcentagem era de 54,9\%, o que significa dizer que há um longo caminho para esta meta ser alcançada.

O gráfico 2 nos permite analisar a situação da Física, onde um pouco mais de $70 \%$ dos docentes não possuem formação adequada para atuar nesta disciplina no ensino médio. Dado preocupante e que está relacionado com as políticas públicas educacionais e com as condições efetivas da carreira docente.

Nunes e Oliveira (2016) evidenciam alguns problemas relacionados à carreira docente, dentre eles: ausência de uma política de Estado efetiva, que garanta atrativo para a profissão, com possibilidade de carreira e desenvolvimento profissional; necessidade de melhorias 
Gráfico 2 - Docentes do ensino médio por formação e por disciplina em que atuam - Brasil, 2015 .

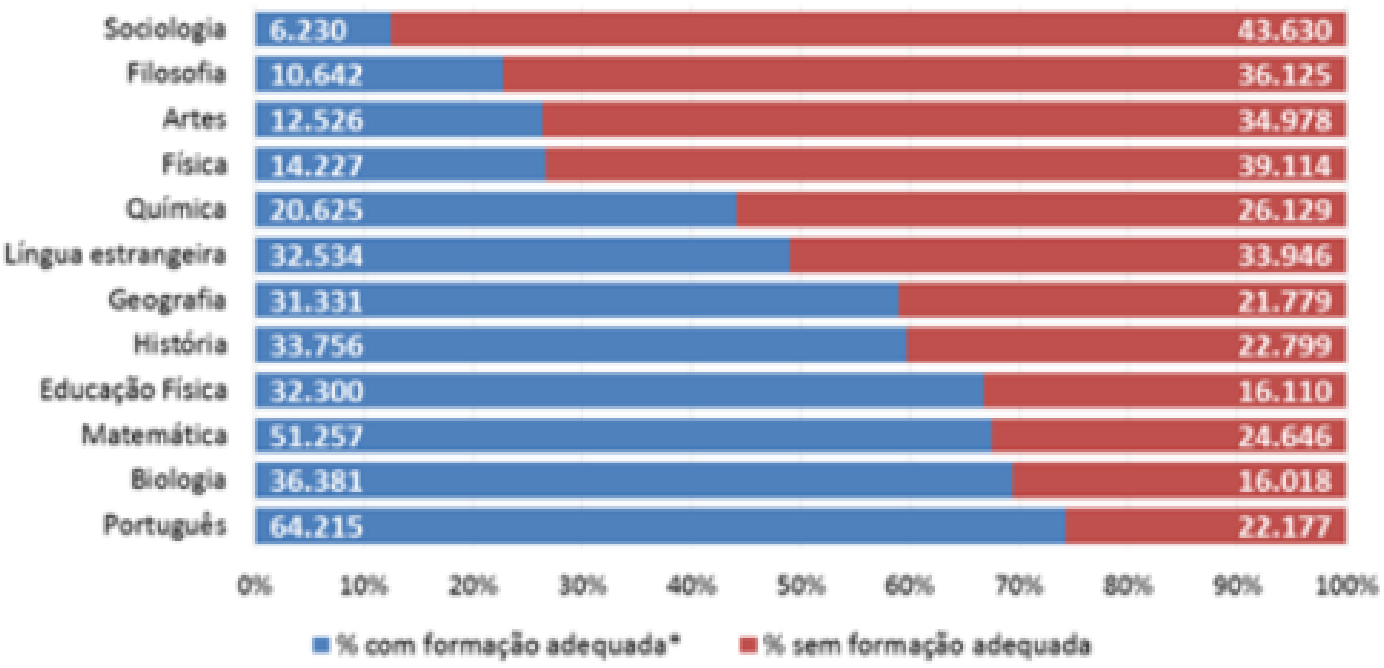

Fonte: Todos Pela Educação.

nas condições de trabalho; o fato da remuneração entre professores estar relacionada ao tempo de serviço e não ao desenvolvimento profissional; ausência de políticas que contribuam para a reversão do quadro de desprestígio da profissão professor, sendo capaz de fomentar um novo imaginário coletivo, com vistas a atrair jovens que desejam efetivamente seguir a carreira docente e não aqueles que, por não terem logrado cursos com reconhecimento social (e, muitas vezes, financeiro), escolhem ser professor por falta de opção. A pesquisa de Leme (2012) comprova a ocorrência deste fenômeno. A autora investigou o perfil de 512 ingressantes nos cursos de licenciatura da Universidade de São Paulo - USP em Pedagogia, Física e Matemática, bem como os fatores presentes para a escolha do curso. A maior parte dos alunos afirmou não possuir o desejo de ser professor na educação básica (52\% na Física; $48 \%$ na Matemática e 30\% na Pedagogia) e o desempenho destes alunos no vestibular da Fuvest foi inferior em relação a todos os demais cursos da USP.

Ainda, Nunes e Oliveira (2016) apontam que em função do pouco reconhecimento social e financeiro e por não haver promoções dentro de um mesmo cargo, muitos professores em exercício acabam por não se interessar em se qualificar e desenvolver processos de desenvolvimento profissional. O processo de promoção ocorre, em muitos contextos, em ordem inversa e prejudicial à sala de aula, uma vez que bons professores são, por vezes, escolhidos e premiados para exercerem outros cargos na área da educação; cargos estes melhores remunerados e distantes da sala de aula. 


\section{Procedimentos metodológicos}

Os dados apresentados nesta seção foram coletados ao longo do ano de 2016 junto aos alunos do primeiro ano do curso noturno de Licenciatura em Física do Instituto Federal de Educação, Ciência e Tecnologia do Estado de São Paulo, campus Registro, localizado no Vale do Ribeira. Inclusive, trata-se do primeiro curso superior deste campus, o que tornou ainda mais empolgante o desenvolvimento deste estudo, na medida em que seria possível acompanhar os estudantes desde a primeira turma.

Para a realização da coleta, foram aplicados quatro questionários semiestruturados. $\mathrm{O}$ primeiro tinha o objetivo de delinear o perfil dos estudantes. O segundo buscou compreender as razões e influências na escolha do curso de Licenciatura em Física. O terceiro analisou as marcas na trajetória escolar que colaboraram para esta escolha e o último identificou, na visão dos estudantes, as experiências de formação que têm contribuído para despertar/aumentar o desejo pela carreira docente em Física.

Os dados provenientes de questões fechadas foram tratados por meio de estatística simples e os provenientes de questões abertas foram categorizados, seguindo o proposto por Bardin (2011) quanto à análise temática, na medida em que "é rápida e eficaz na condição de se aplicar a discursos diretos (significações manifestas) e simples” (ibidem, p. 201).

\section{Resultados e análise dos dados}

Os resultados e análises são apresentados em quatro partes, cada uma delas fazendo referência a um questionário específico aplicado aos estudantes.

\section{IV.1 Quem são os ingressantes na Licenciatura em Física no IFSP de Registro?}

O corpo discente é formado por 40 alunos, dos quais 33 participaram da etapa inicial da pesquisa, sendo 39,39\% do sexo feminino e 60,61\% do sexo masculino, o que demonstra a presença ainda forte do sexo masculino nesta área. A faixa etária predominante é de até 24 anos $(78,78 \%)$, grande parte é solteiro $(81,82 \%)$ e não possui filhos $(87,88 \%)$. A internet foi apontada como o principal lazer $(48,48 \%)$, seguido de leitura de livros (39,39\%). Ainda, $60,61 \%$ se declararam brancos, $27,27 \%$ pardos ou mulatos, $9,09 \%$ negros e $3,03 \%$ de origem oriental.

A turma é formada essencialmente por alunos provenientes do Vale do Ribeira (87.87\%), o que indica que o curso/instituto está contribuindo para a formação de pessoas de sua própria região, carente de cursos superiores, sobretudo de instituições públicas. Alguns poucos alunos $(15,15 \%)$ já possuíam uma graduação (Biomedicina, Ciências com habilitação em Matemática e Pedagogia) e 18,18\% iniciaram um curso antes do ingresso na licenciatura, mas não concluíram.

Interessante observar que $84,85 \%$ dos alunos estudaram em escola pública durante todo o ensino médio, 27,27\% ingressaram na Licenciatura em Física no ano seguinte a con- 
clusão do ensino médio e 45,45\% o fizeram entre 1 a 5 anos após o término deste nível de ensino.

Sobre a questão da moradia, $69,70 \%$ dos estudantes residem com pais e/ou outros parentes, 21,21\% com esposo(a) e/ou filhos, 6,06\% com amigos e 3,03\% sozinhos. Já sobre a renda mensal dos alunos, mais da metade declarou receber até 3 salários mínimos (54,55\%), $42,42 \%$ possuem renda variando de 3 a 10 salários mínimos, com aproximação maior do limite inferior, e apenas 3,03\% possui uma renda superior a 11 salários mínimos. Estes dados sobre renda não apenas vão ao encontro daqueles evidenciados por Gatti (2014) a partir dos questionários do ENADE, como os superam, já que neste caso é bastante superior a porcentagem de alunos com renda de até 3 salários mínimos. Já a escolaridade dos pais dos estudantes pode ser observada a seguir:

Tabela 1 - Grau de escolaridade dos pais.

\begin{tabular}{|l|c|c|}
\hline \multicolumn{1}{|c|}{ Grau de escolaridade } & Mãe & Pai \\
\hline Nenhuma. & $3,03 \%$ & $0,00 \%$ \\
\hline Ensino Fundamental I. & $6,06 \%$ & $39,39 \%$ \\
\hline Ensino Fundamental II. & $9,09 \%$ & $21,21 \%$ \\
\hline Ensino Médio. & $51,52 \%$ & $18,18 \%$ \\
\hline Ensino Superior. & $30,30 \%$ & $15,15 \%$ \\
\hline Não respondeu. & $0,00 \%$ & $6,06 \%$ \\
\hline
\end{tabular}

Fonte: Elaborado pelos autores.

A tabela 1 praticamente evidencia uma inversão. O percentual do pai decresce à medida que vai aumentando o grau de escolaridade, ao passo que da mãe dos alunos aumenta, chegando a mais da metade a quantidade de mães ao menos com ensino médio $(51,52 \%)$. Ainda, com relação ao ensino superior, apenas $15,15 \%$ dos pais dos alunos chegaram a tal etapa, sendo que o percentual das mães representa o dobro deste valor no mesmo nível de ensino. De acordo com o Instituto Brasileiro de Geografia e Estatística - IBGE (2014), a escolarização feminina tem avançado, sobretudo nas faixas etárias de 15 a 29 e 30 a 59 anos de idade, apontando ser, de maneira geral, superior em mulheres. Contudo, cabe destacar que, no Brasil, quanto maior a escolaridade, maior a desigualdade de renda entre homem e mulher (LISBOA, 2015).

A tabela 2 aponta que a maior parte dos alunos não trabalha $(60,61 \%)$. Este dado diverge do contexto geral apresentado por Gatti (2014), em que a esmagadora maioria dos estudantes de licenciatura trabalham, chegando a ser apenas $2 \%$ a porcentagem daqueles que não trabalham e são inteiramente custeados pela família. No entanto, podemos concluir a partir da tabela 2 que uma parcela significativa (quase 40\%) divide seu tempo entre estudo e trabalho, além de demais compromissos. Isso certamente reduz o tempo de dedicação aos estudos e a 
possibilidade de participação em atividades diversificadas (de pesquisa, extensão, cultural etc.) que ocorrem em horário diferente das aulas.

Tabela 2 - Situação de trabalho dos alunos.

\begin{tabular}{|l|c|}
\hline \multicolumn{1}{|c|}{ Situação de Trabalho } & Porcentagem (\%) \\
\hline Não trabalha e é sustentado pela família. & 60,61 \\
\hline Trabalha e recebe ajuda da família. & 3,03 \\
\hline Trabalha e se sustenta. & 9,09 \\
\hline Trabalha e contribui com o sustento da família. & 18,18 \\
\hline Trabalha e é o principal responsável pelo sustento da família. & 9,09 \\
\hline
\end{tabular}

Fonte: Elaborado pelos autores.

\section{IV.2 A escolha da carreira docente e o desejo de ser professor}

Uma das perguntas que nos colocamos nesta pesquisa foi se a escolha da carreira docente pelo aluno estava acompanhada do desejo de ser professor, ou seja, do desejo de vivenciar a profissão docente, de lecionar na educação básica. Sabemos que "as escolhas a serem feitas não dizem respeito somente às características pessoais, mas principalmente ao contexto histórico e ao ambiente sociocultural em que o jovem vive" (FUNDAÇÃO CARLOS CHAGAS, 2009, p. 10). Trata-se daquilo que discute Bourdieu (2007) sobre "o gosto pelo possível". Em outras palavras, muitas variáveis estão em jogo no momento da escolha de uma carreira: aspectos sociais, perfil escolar, sexo, etnia, idade, entre outras, que influenciam e "ajustam" o gosto ao que é possível de ser conquistado.

Quando questionados sobre a razão para cursar Licenciatura em Física, apenas $24,24 \%$ dos alunos declararam ter "vontade de lecionar". Todas as categorias estão descritas na tabela $3(\mathrm{~N}=33)$.

Tabela 3 - Razões para a escolha do Curso de Licenciatura em Física.

\begin{tabular}{|l|c|}
\hline \multicolumn{1}{|c|}{ Razões } & Porcentagem (\%) \\
\hline Identificação com a Física. & 48,48 \\
\hline Gosto por exatas. & 45,45 \\
\hline Vontade de lecionar. & 24,24 \\
\hline Física como ponte para outro curso e oportunidades. & 21,21 \\
\hline Instituição pública federal. & 21,21 \\
\hline Pela proximidade de sua residência. & 12,12 \\
\hline Demanda de profissionais na área. & 12,12 \\
\hline
\end{tabular}




\begin{tabular}{|l|c|} 
Falta de opção de cursos na região. & 9,09 \\
\hline Complementação de renda. & 6,06 \\
\hline Seguir na área da pesquisa /acadêmica. & 6,06 \\
\hline
\end{tabular}

Fonte: Elaborado pelos autores.

A segunda questão do questionário sobre a escolha da carreira solicitava que os alunos descrevessem as pessoas que influenciaram na escolha pelo curso. Boa parte da turma declarou não ter sofrido influência (45,45\%). Já 27,27\% relataram que a família colaborou para esta decisão e $24,24 \%$ apontaram que a escolha pelo curso de Licenciatura em Física teve a influência de um professor que marcou positivamente sua trajetória escolar.

Interessante observar que, quando questionados sobre o que consideravam ser a principal contribuição do curso, as respostas foram:

Tabela 4 - Principal contribuição do curso de Licenciatura em Física na visão dos alunos.

\begin{tabular}{|l|l|}
\hline \multicolumn{1}{|c|}{ Opção } & Porcentagem (\%) \\
\hline A aquisição de formação profissional. & 30,30 \\
\hline A obtenção de diploma de nível superior. & 27,27 \\
\hline A aquisição de formação teórica. & 15,15 \\
\hline Melhores perspectivas de ganhos financeiros. & 9,09 \\
\hline A aquisição de cultura geral. & 6,06 \\
\hline Não respondeu. & 12,12 \\
\hline
\end{tabular}

Fonte: Elaborado pelos autores.

As razões apontadas pelos alunos para a escolha do campus de Registro para cursar o ensino superior nos oferecem algumas pistas. Quase a metade da turma $(48,48 \%)$ relatou ser devido à localização próxima à sua residência e 69,70\% afirmaram que escolheram aquela instituição e campus por se tratar de uma instituição pública de ensino superior. Apenas $12,12 \%$ dos alunos afirmaram que a escolha por estudar no IFSP - Registro deve-se ao fato de a instituição ter o curso pretendido. Desta forma, fica evidente que o desejo de ser professor não é a principal razão para estes estudantes terem escolhido o curso de Licenciatura em Física. No entanto, quando questionados sobre o que pretendem fazer após se formarem como professores de Física, 63,64\% dos alunos afirmaram "lecionar", 45,45\% declararam desejar "continuar os estudos", 27,27\% "realizar outro curso", 12,12\% "conseguir uma boa colocação no mercado de trabalho" e 9,09\% pretendem "realizar concursos que exigem nível superior".

Este desencontro de afirmações revela, para uma parte dos alunos, uma entrada na licenciatura com algumas dúvidas, reservas ou mesmo um sentimento de que o curso de Licen- 
ciatura em Física é o que é possível para o hoje e que, de repente, no amanhã, possa vir a ser uma carreira a ser seguida. Tais dados demonstram a necessidade de acompanhamento dos alunos ao longo da graduação, assim como quando se tornarem egressos, percebendo o movimento de entrada no mundo do trabalho e a forma como ele se efetiva ou não.

\section{IV.3 As marcas na trajetória escolar e a escolha profissional docente}

A compreensão das marcas pessoais construídas durante o percurso singular do indivíduo apresenta-se como uma possibilidade de formação, pois possibilita ao sujeito em formação depreender-se como autor de sua trajetória formativa (ROZEK, 2013). Com a elaboração de relatos autobiográficos, busca-se reconstruir a história de formação do licenciando. $\mathrm{O}$ futuro docente é detentor de saberes, impressões e experiências que, acumuladas em sua trajetória de aluno e mergulhadas no seu próprio eu, em suas práticas e vivências, possibilita-lhe atribuir valor à sua narrativa, enquanto história de vida de si, enquanto cotidiano pessoal e profissional construído como ator e autor de sua própria história.

A importância de investigações que envolvem narrativas autobiográficas, memórias e trajetórias de formação, deve-se às suas contribuições tanto para os sujeitos de pesquisa quanto para os pesquisadores. Os estudantes, ao serem inseridos em momentos de reflexão acerca de suas experiências escolares, reconstroem suas trajetórias e atribuem novos significados às vivências, construindo a ideia do que é ser professor, aluno, diretor e outros atores educacionais. O pesquisador, por sua vez, aprende por meio das histórias de vida, das memórias e das representações de seus alunos e pode, em trabalho colaborativo, perceber (ao mesmo tempo em que ajuda os sujeitos de pesquisa a perceberem) as experiências significativas, as dificuldades, impasses, alegrias e angústias que estão envolvidos no processo de ensino e aprendizagem e os modos como os sujeitos participantes enxergam a escola, o seu papel e a profissão professor. Investigações deste tipo favorecem, portanto, a análise da natureza das relações entre as experiências escolares iniciais e a identidade docente (CATANI; BUENO; SOUSA, 2000).

Os significados e representações que são construídos na e sobre a escola estão intimamente ligados ao fazer pedagógico dos futuros professores. A recuperação e reflexão sobre estes aspectos colaboram para os sujeitos pensarem o tipo de prática, de professor e de ambiente educacional que desejam construir: quer seja semelhante ao que vivenciaram ou completamente diferente das experiências por quais passaram. Isto porque tais experiências, como salienta Catani, Bueno e Sousa (2000), não desaparecem da história do sujeito, ao contrário, ainda que pouco perceptíveis, permanecem vivas e atuantes ao longo da formação e dão suporte às relações que os estudantes, futuros professores, acabam por estabelecer com a escola, com o conhecimento, com seus alunos e com a própria profissão. Em consonância com esta proposição, Nunes e Cunha (2005) argumentam que os estudos biográficos procuram enfatizar a convicção de que todos nós somos herdeiros daquilo que vivenciamos no passado e que é possível tirar proveito pedagógico deste passado ao refletir sobre as experiências pregressas. 
Assim, buscamos perceber quais são as "recordações-referências" (SOUZA, 2007) dos estudantes sobre as relações humanas estabelecidas em sala de aula e na escola, sobre o processo de aprendizagem e avaliação, sobre o professor. Acreditamos que a retomada de si, de sentimentos, vivências e aprendizagens pode contribuir significativamente para a construção do processo de identidade profissional do professor e nos auxiliar na tarefa de compreender as razões para a escolha da carreira docente.

Esta parte da pesquisa, constituída por um questionário com 4 perguntas abertas, contou com a participação de 14 estudantes. Esclarecemos que dos 40 estudantes inicialmente matriculados, somente 28 estavam frequentando o curso em julho de 2016, quando do início da aplicação deste questionário.

A tabela 5 aponta as lembranças boas e ruins que os alunos possuíam de professores que marcaram sua formação.

Tabela 5 - Lembrança dos alunos sobre professores que marcaram sua formação.

\begin{tabular}{|l|c|}
\hline \multicolumn{1}{|c|}{ Categorias } & Porcentagem (\%) \\
\hline Contribuição na formação da personalidade do aluno. & 50,00 \\
\hline Professor que dialogava (amigo). & 42,86 \\
\hline Professores apaixonados pela profissão. & 35,71 \\
\hline Professores mal preparados. & 28,57 \\
\hline Prestígio a professores de Língua Portuguesa. & 28,57 \\
\hline Direcionamento ao gosto pelas exatas. & 21,43 \\
\hline Desentendimento com algum professor. & 14,29 \\
\hline Professor descompromissado. & 7,14 \\
\hline Professor arrogante/ofensivo. & 7,14 \\
\hline
\end{tabular}

Fonte: Elaborado pelos autores.

Podemos perceber que metade dos estudantes afirmou que os professores que passaram por sua vida, seja na educação infantil, no ensino fundamental ou médio, contribuíram de forma significativa para a formação de sua personalidade. Neste sentido, Libâneo (2015, p. 50) argumenta que o trabalho dos professores consiste em "ajudar o aluno, por meio de conteúdos, a adquirir capacidades para novas operações mentais ou modificar as existentes, com o que se operam mudanças qualitativas em sua personalidade".

A categoria "professor que dialogava (amigo)" aparece em segundo lugar, e "professores apaixonados pela profissão", em terceiro, demonstrando que, na visão de boa parte dos alunos, boas recordações são provenientes de professores abertos ao diálogo, à troca, ao compartilhamento, bem como aqueles que expressam, por meio de suas ações diárias, apreço por sua profissão. 
É curioso perceber que 28,57\%, dos alunos de um curso de Licenciatura em Física expressaram que foram professores da área de Língua Portuguesa que marcaram fortemente sua formação. Outro dado curioso aponta que apenas $21,43 \%$ dos estudantes relataram que tiveram professores que estimularam o gosto pelas ciências exatas.

Ainda, é importante destacar que $28,57 \%$ dos estudantes relataram que tiveram professores que não estavam preparados para a docência, assim como 7,14\% afirmaram ter tido aulas com professores descompromissados com a prática escolar, e 7,14\% se depararam com professores arrogantes e ofensivos ao longo de sua permanência na escola. Trata-se de dados preocupantes, ainda que não seja a manifestação da maior parte dos alunos. Despreparo e descompromisso frente à profissão e hostilidade para com os alunos explicita a necessidade de (re) pensar a formação inicial e continuada de professores para a promoção de mudanças na cultura profissional estabelecida, que, para além do domínio de conteúdos, desenvolva consciência ética e compromisso com a aprendizagem dos alunos.

A segunda questão solicitava aos alunos que respondessem como os seus professores do ensino médio os ajudavam a superar dificuldades de aprendizagem. A tabela 6 reúne as respostas a esta questão.

Tabela 6 - Atuação dos professores do ensino médio frente às dificuldades de aprendizagem dos alunos.

\begin{tabular}{|l|c|}
\hline \multicolumn{1}{|c|}{ Categorias } & $\begin{array}{c}\text { Porcentagem } \\
(\%)\end{array}$ \\
\hline Os professores eram atenciosos. & 50,00 \\
\hline $\begin{array}{l}\text { O ensino era fraco (professores normalmente não se importavam com } \\
\text { os alunos). }\end{array}$ & 35,71 \\
\hline O aluno não apresentou dificuldades. & 28,57 \\
\hline $\begin{array}{l}\text { Os professores ofereciam um tempo de atendimento pós-horário de au- } \\
\text { la. }\end{array}$ & 21,43 \\
\hline Os professores resolviam exercícios. & 21,43 \\
\hline Os professores não ajudavam. & 21,43 \\
\hline Os professores incentivavam o estudo. & 14,29 \\
\hline
\end{tabular}

Fonte: Elaborado pelos autores.

Apenas metade dos estudantes considerou que seus professores eram atenciosos. Ainda, 35,71\% relataram que o ensino era fraco e, normalmente, os professores não se importavam com suas dificuldades. Neste mesmo caminho, 21,43\% afirmaram que os professores simplesmente não os ajudavam quando apresentavam dúvidas e, por isso, buscavam cessar suas dificuldades por outros meios. Há que se questionar a existência de diálogo e abertura na relação pedagógica estabelecida entre professor e aluno. 
Aspectos positivos foram relatados, apesar de serem descritos pela minoria dos estudantes: 21,43\% afirmaram que seus professores os ajudavam oferecendo atendimento após a aula; $21,43 \%$ mencionaram que seus professores auxiliavam na resolução de exercícios e $14,29 \%$ expressaram que seus professores incentivavam o estudo, o que de maneira contínua deve ser considerado como uma atitude de grande importância na formação dos alunos.

A terceira questão se referia ao ambiente escolar a que esses alunos estavam sujeitos no ensino médio. Tal pergunta interpelava sobre aspectos como o prédio, as relações estabelecidas com colegas, coordenadores, diretores e demais atores educacionais. A tabela 7 apresenta as respostas dos estudantes.

Tabela 7 - Ambiente da escola no ensino médio.

\begin{tabular}{|l|c|}
\hline \multicolumn{1}{|c|}{ Categorias } & Porcentagem (\%) \\
\hline Bom relacionamento com os colegas. & 71,43 \\
\hline Prédio com boa estrutura/instalação. & 57,14 \\
\hline Ambiente escolar agradável/acolhedor. & 50,00 \\
\hline Boa relação com a coordenação. & 42,86 \\
\hline Boa relação com a direção. & 35,71 \\
\hline Bom relacionamento com os funcionários da escola. & 35,71 \\
\hline O ambiente escolar era conturbado. & 21,43 \\
\hline Prédio da escola antigo/ mal conservado. & 21,43 \\
\hline Escola com estrutura inadequada. & 21,43 \\
\hline Relacionamento ruim com os colegas (rejeição/bullying/ humilhações). & 21,43 \\
\hline
\end{tabular}

Fonte: Elaborado pelos autores.

A maioria dos estudantes $(71,43 \%)$ afirmou possuir bom relacionamento com os colegas. No entanto, apenas $50 \%$ consideraram o ambiente escolar como um local agradável/acolhedor, o que aponta a necessidade de reflexão durante a formação sobre a organização do espaço e o clima escolar, assim como sobre as ações práticas de acolhimento dos estudantes.

Já com a coordenação, 42,86\% afirmaram possuir boa relação. Esse número cai para $35,71 \%$ quando o bom relacionamento se dirige à direção e aos funcionários da escola. Esses dados nos mostram que nem mesmo $50 \%$ dos alunos manifestaram possuir boa relação com a coordenação e direção. Deduzimos que isto pode ocorrer em função da gestão escolar estar ainda distante do pedagógico, sendo mais burocrática e administrativa do que próxima às questões da aprendizagem e relação pedagógica. 
Ainda, destacamos que $21,43 \%$ dos alunos afirmaram que seu ensino médio foi marcado por um ambiente escolar conturbado, com estrutura inadequada e mal conservada e que sofreram rejeição e humilhação por parte dos colegas.

A última questão perguntava aos estudantes o que consideravam ser um bom professor. As respostas estão categorizadas na tabela a seguir.

Tabela 8 - Significados de "bom professor" na visão dos estudantes.

\begin{tabular}{|l|c|}
\hline \multicolumn{1}{|c|}{ Categorias } & Porcentagem (\%) \\
\hline $\begin{array}{l}\text { Levar o conhecimento adiante de forma que todos os alunos possam } \\
\text { compreendê-lo. }\end{array}$ & 57,14 \\
\hline Ser atencioso, fazer todo o possível para ajudar o aluno. & 57,14 \\
\hline $\begin{array}{l}\text { Manifestar a importância dos estudos à vida e às perspectivas de um } \\
\text { novo mundo. }\end{array}$ & 42,86 \\
\hline Saber lidar com características pessoais. & 21,43 \\
\hline Dominar o conteúdo e saber ensinar. & 21,43 \\
\hline $\begin{array}{l}\text { Ter em mente que mesmo um professor pode não saber todas as res- } \\
\text { postas. }\end{array}$ & 14,29 \\
\hline Não trazer problemas pessoais para a sala de aula. & 14,29 \\
\hline Cumprir com os prazos. & 14,29 \\
\hline Ser um profissional ético. & 14,29 \\
\hline
\end{tabular}

Fonte: Elaborado pelos autores.

Por se tratar de um curso de licenciatura, o graduando precisa estar consciente de que sua prática profissional será exercida em sala de aula, ainda que varie o nível e a modalidade. Assim, ao rememorar fatos que ocorreram em sua trajetória escolar, é possível recuperar lembranças importantes que marcaram a formação e que contribuíram para a construção da representação social sobre ser "bom professor", seja a partir de boas ou más recordações. Libâneo (2015) aponta que muitas pesquisas têm revelado que a referência do professor, no exercício da docência, está muito mais ligada à sua experiência vivida na condição de estudante do que aos conhecimentos teóricos aprendidos durante a sua formação de professor.

A tabela 8 evidencia que, para a maior parte dos alunos de Licenciatura em Física que participaram da pesquisa $(57,14 \%)$, são características essenciais de um bom professor: "levar o conhecimento adiante de forma que todos os alunos possam compreendê-lo" e "ser atencioso e fazer todo o possível para ajudar o aluno". Ainda, boa porcentagem considera ser: "manifestar a importância dos estudos à vida e a perspectiva de um novo mundo" (42,86\%). Depreendemos destas respostas ser fundamental que o trabalho desenvolvido pelo professor possa conduzir, invariavelmente, os alunos à construção de conhecimentos, à aprendizagem signifi- 
cativa. $\mathrm{O}$ compromisso com os alunos, a atenção às suas dificuldades e a aproximação dos conteúdos às suas realidades parecem ser características importantes para estes estudantes.

Para 21,43\% dos estudantes é preciso que o professor saiba lidar com suas características pessoais, como exemplifica a resposta abaixo de um dos estudantes:

"Ser capaz de, ao mesmo tempo, possuir bom humor e manter a disciplina em sala de aula. Ser respeitado, mas não impor um regime autoritário. Ser compreensível e não deixar a sala se tornar uma baderna, se impor, sem ser taxado como uma autoridade severa".

Apesar de um número pequeno $(21,43 \%)$ apontar que um bom professor precisa dominar o conteúdo de sua área e saber ensinar, ressaltamos a importância não apenas das disciplinas específicas, mas também das pedagógicas, que se dedicam a formar o professor, a leválo a refletir sobre o processo de ensino e aprendizagem, a compreender questões educacionais, a relacionar teoria e prática. Para Gatti (2010), a prevalência da formação com ênfase na área disciplinar específica em detrimento da formação pedagógica é histórica, o que nos coloca a difícil tarefa de pensar o currículo de formação de professores.

Ainda, é curioso verificar que para 14,29\% dos estudantes, ser um bom professor permite não saber todas as respostas. Exemplificamos com um trecho da resposta de um dos alunos: "a questão de dizer ao aluno que desconhece tal resposta não é vergonhoso ou trágico. Ambos, professor e aluno, podem procurar pelas respostas". Trata-se de uma resposta madura apresentada por poucos, mas que já aponta na direção de mudança de mentalidade sobre a visão de que o professor é o único detentor do conhecimento verdadeiro e que possui todas as respostas. Neste sentido, Paulo Freire já afirmava: "como professor devo saber que sem a curiosidade que me move, que me inquieta, que me insere na busca, não aprendo, nem ensino" (FREIRE, 1996, p. 95). Portanto, é uma profissão de movimento, de busca constante para "ser mais", para saber mais.

\section{IV.4 A carreira docente a as experiências de formação na graduação}

Esta parte apresenta e discute as respostas de 22 estudantes a um questionário composto por três questões abertas. A primeira desejava identificar as experiências, práticas e atividades propostas pelos professores da Licenciatura em Física que colaboraram, na visão dos estudantes, para sua formação docente.

Tabela 9 - Atividades propostas pelos professores que colaboraram, na visão dos alunos, para sua formação enquanto futuro professor.

\begin{tabular}{|l|c|}
\hline \multicolumn{1}{|c|}{ Categorias } & Porcentagem (\%) \\
\hline Realização de uma aula nas escolas para alunos do Ensino Médio. & 31,82 \\
\hline Estudos sobre educação e sociedade. & 27,27 \\
\hline Todas as experiências colaboraram com a formação docente. & 27,27 \\
\hline
\end{tabular}




\begin{tabular}{|l|c|} 
Aprender com a didática dos professores. & 22,73 \\
\hline $\begin{array}{l}\text { Experiências que articulam conhecimentos teóricos e atividades } \\
\text { práticas do cotidiano escolar. }\end{array}$ & 18,18 \\
\hline Realização de seminários. & 18,18 \\
\hline Realização de experimentos em aula. & 13,64 \\
\hline Trabalhar na SNCT 3 do IFSP-Registro. & 13,64 \\
\hline Resolver exercício em lousa. & 9,09 \\
\hline Aprender a realizar pesquisas. & 9,09 \\
\hline A mescla de disciplinas de ciências humanas e exatas no curso. & 4,55 \\
\hline Ter aula com professor apaixonado pela docência e pela Física. & 4,55 \\
\hline
\end{tabular}

Fonte: Elaborado pelos autores.

Para esta turma de primeiro ano de Licenciatura em Física, a realização de uma aula em escolas de ensino médio da região do Vale do Ribeira foi a atividade mais citada $(31,82 \%)$ como aquela que contribuiu para a futura atuação como docente. Percebe-se, desta forma, a grande importância que os alunos atribuem às experiências práticas, pedagógicas, próprias da ação docente. Sabemos que as disciplinas que contribuem para desenvolver saberes didáticopedagógicos são essenciais em cursos de formação de professores, na medida em que colaboram para o desenvolvimento da profissionalidade dos alunos (D’AVILA; LEAL, 2015). Para Gatti (2016), é essencial uma formação que auxilie os estudantes a lidar com desafios atuais da sala de aula, da escola e da educação, de maneira geral. Assim, acreditamos que o processo de planejamento de uma aula, a sua realização, bem como a produção de relatório sobre todo o processo é uma experiência valiosa e significativa em cursos de formação de professores.

Um olhar atencioso sobre os dados apresentados na tabela 9 revela que os estudantes, de maneira geral, atribuíram importância a aspectos pedagógicos e não apenas específicos, de conteúdos próprios da Física. Este fato aponta que, mesmo de forma talvez ainda pouco consciente, por se tratar de uma turma de primeiro ano, os estudantes percebem que a "mescla de disciplinas de ciências humanas e exatas no curso", "estudos sobre educação e sociedade", "realização de seminários", "aprender com a didática dos professores", "trabalhar na SNCT do IFSP-Registro", "aprender a realizar pesquisas" e "experiências que articulam conhecimentos teóricos e atividades práticas do cotidiano escolar" colaboram para sua formação e futura prática docente.

A segunda questão, por sua vez, solicitava aos alunos que relatassem alguma atividade ou experiência vivenciada no curso que despertou ou aumentou o desejo pela carreira docente. Os dados podem ser observados na tabela 10.

Podemos perceber que as respostas dos estudantes a esta questão possuem relação direta com a anterior. Novamente, "realizar uma aula para uma turma do ensino médio" aparece

\footnotetext{
${ }^{3}$ SNCT - Semana Nacional de Ciência e Tecnologia.
} 
como a experiência mais citada, mas, neste caso, é indicada como aquela que colaborou para despertar/ampliar o desejo pela carreira docente.

Tabela 10 - Atividades que despertaram/ampliaram o desejo do aluno pela carreira docente.

\begin{tabular}{|l|c|}
\hline \multicolumn{1}{|c|}{ Categorias } & Porcentagem (\%) \\
\hline Poder realizar uma aula para uma turma do Ensino Médio. & 27,27 \\
\hline $\begin{array}{l}\text { A interação com alunos e professores durante a SNCT do IFSP- } \\
\text { Registro. }\end{array}$ & 22,73 \\
\hline $\begin{array}{l}\text { O curso, de maneira geral, está colaborando com a vontade de ser pro- } \\
\text { fessor. }\end{array}$ & 13,64 \\
\hline $\begin{array}{l}\text { Matérias pedagógicas que permitem o conhecimento sobre o que é ser } \\
\text { professor. }\end{array}$ & 9,09 \\
\hline Realização de experimentos. & 9,09 \\
\hline Nada despertou ou aumentou o desejo em seguir à carreira docente. & 9,09 \\
\hline Atividades de cálculo. & 4,55 \\
\hline O curso aumentou o desejo pela carreira de exatas. & 4,55 \\
\hline Realizar pesquisas sobre a área da educação. & 4,55 \\
\hline A base teórica e didática de bons professores. & 4,55 \\
\hline Realização de seminários. & 4,55 \\
\hline O aluno não respondeu. & 4,55 \\
\hline
\end{tabular}

Fonte: Elaborado pelos autores.

Com exceção de atividades de cálculo (4,55\%) e de 9,09\% dos alunos que declararam que nenhuma atividade neste primeiro ano de Licenciatura em Física colaborou para avivar o desejo em ser professor, as demais experiências e atividades relatadas têm relação com as questões didático-pedagógicas e de formação geral. Estes dados trazem questões a serem pensadas no currículo de cursos de licenciatura e no planejamento das aulas, uma vez que, na visão dos estudantes, a proximidade com o exercício e ambiente da profissão colabora para o seu desenvolvimento profissional e desejo de ser professor. Ainda, sabemos que experiências que relacionam teoria e prática possibilitam o conhecimento da dinâmica de uma sala de aula e escola, futuro local de trabalho dos licenciandos.

A terceira e última questão solicitava que os alunos discorressem sobre seus sentimentos em relação ao curso, bem como sobre o desejo de nele permanecer.

Apesar de mais da metade dos alunos $(72,73 \%)$ desejar finalizar o curso, não se pode ignorar o fato de que $22,73 \%$ pretendem realizar outro curso e $13,64 \%$ pensam na possibilidade de seguir outra carreira, estando em dúvida sobre a finalização da licenciatura ou o trancamento do curso. No entanto, $50 \%$ apontaram estarem felizes nesta graduação e $22,73 \%$ revelaram que, apesar das dificuldades, também se sentem felizes. Assim, podemos concluir que, 
de maneira geral, $72,73 \%$ da turma estão felizes na realização do curso de Licenciatura em Física.

Tabela 11 - Sentimento dos alunos em relação ao curso.

\begin{tabular}{|l|c|}
\hline \multicolumn{1}{|c|}{ Categorias } & Porcentagem (\%) \\
\hline Desejo de finalizar o curso. & 72,73 \\
\hline Está feliz no curso. & 50,00 \\
\hline Sente dificuldades, mas está feliz no curso. & 22,73 \\
\hline Pretende realizar outro curso. & 22,73 \\
\hline Há pretensão de se especializar na área. & 22,73 \\
\hline Há possibilidade de seguir outra carreira. & 13,64 \\
\hline Está parcialmente feliz. & 9,09 \\
\hline É um dos poucos cursos de nível superior de acesso gratuito na região. & 9,09 \\
\hline Não pretende concluir o curso. & 4,55 \\
\hline Não está feliz no curso. & 4,55 \\
\hline
\end{tabular}

Fonte: Elaborado pelos autores.

Destacamos que $9,09 \%$ dos estudantes não descreveram seu sentimento em relação ao curso, apenas afirmaram que o motivo de nele se matricularem deve-se ao fato de ser "um dos poucos cursos de nível superior gratuito na região". Ainda, 4,55\% afirmaram não estar felizes no curso, bem como não possuírem o desejo de concluir a licenciatura e 9,09\% declararam estar parcialmente felizes. Percebemos, portanto, indecisão por parte de um número significativo de alunos sobre a permanência no curso e a escolha da carreira docente. Relembramos que, quando questionados sobre as razões para a escolha do curso de Licenciatura em Física, a maior parte respondeu identificação com a Física e gosto pelas exatas e somente $24,24 \%$ apontaram ser o desejo de lecionar. Ainda, houve aqueles que justificaram que o curso era ponte para outras oportunidades, próximo a suas residências e por se tratar de uma instituição gratuita. Desta forma, a questão da dúvida na realização do curso parece estar mais ligada à (não) identificação com a docência, à falta de opções de cursos de nível superior gratuitos na região do Vale do Ribeira e a proximidade entre a instituição e a residência dos alunos.

\section{Considerações finais}

Os dados obtidos nesta pesquisa permitiram conhecer melhor o perfil dos alunos, suas condições de vida, trajetória escolar, representação sobre ser um bom professor, bem como o processo de escolha da licenciatura e desejo de seguir na carreira docente. As análises sugerem que os estudantes optaram pela Licenciatura em Física muito mais por ser um curso não 
pago e próximo de suas residências do que pela identificação com a profissão docente. $\mathrm{O}$ fato de muitos apontarem gostar da Física e das exatas não pode ser tomado como sinônimo de gostar de lecionar, verbo pouco encontrado nas respostas dos alunos.

No entanto, diante do desprestígio econômico e simbólico da profissão docente no Brasil, não se torna difícil entender as razões da baixa frequência da palavra "lecionar" nesta pesquisa. No caso da Licenciatura em Física, curso que revela taxas de reprovação e abandono altas, o desejo do exercício do magistério parece ser ainda mais ínfimo, basta a consulta e comparação de dados com relação ao número de cursos oferecidos, de matrículas e concluintes. Contudo, mais da metade dos estudantes investigados $(63,64 \%)$ apontou enxergar a possibilidade de exercer a profissão docente após formado.

Por fim, acreditamos ser importante que novas investigações acompanhem a trajetória dos estudantes de cursos de licenciatura, percebendo as mudanças em suas atitudes e escolhas, suas motivações para permanecerem no curso e na profissão e as experiências formativas que contribuem, na visão deles, para a aprendizagem da profissão e conscientização crítica da prática educacional. Ainda, a investigação dos futuros egressos poderá auxiliar neste processo, sendo possível analisar as razões para os abandonos e permanências na área da educação, bem como as contribuições do curso para o desenvolvimento profissional e entrada no mundo do trabalho.

\section{Referências}

BARDIN, L. Análise de conteúdo. São Paulo: Edições 70, 2011.

BOURDIEU, P. A distinção: crítica social do julgamento. Porto Alegre: Zouk, 2007.

CATANI, D. B.; BUENO, B. A. O.; SOUSA, C. P. O amor dos começos: por uma história das relações com a escola. Cadernos de Pesquisa, n. 111, p. 151-171, 2000. Disponível em: <http://publicacoes.fcc.org.br/ojs/index.php/cp/article/viewFile/634/ 652>. Acesso em: 27 nov. 2016.

D’ÁVILA, C. M.; LEAL, L. B. Docência universitária e formação de professores - saberes pedagógicos e constituição da profissionalidade docente. Linhas Críticas, Brasília, DF, v. 21, n. 45, p. 467-485, mai./ago. 2015.

FOLHA DE SÃO PAULO. Nenhum jovem quer virar professor no Brasil, mostra exame da OCDE. Folha de São Paulo, 07 dez. 2016. Disponível em: <http://www1.folha.uol.com. br/colunas/ericafraga/2016/12/1839126-nenhum-jovemquer-se-tornar-professor-no-brasil. shtml>. Acesso em: 12 dez. 2016.

FREIRE, P. Pedagogia da autonomia: saberes necessários à prática educativa. 8. ed. São Paulo: Paz Terra, 1996. 
FUNDAÇÃO CARLOS CHAGAS. A atratividade da carreira docente no Brasil. Fundação Victor Civita SÃO PAULO, 2009. Disponível em: <http://docplayer.com.br /322180-Aatratividade-da-carreira-docente-no-brasil.html>. Acesso em: 05 jul. 2016.

GATTI, B. A. Formação de professores no Brasil: características e problemas. Educação \& Sociedade, Campinas, v. 31, n. 113, p. 1355-1379, out.-dez. 2010.

GATTI, B. A. Educação, escola e formação de professores: políticas e impasses. Educar em Revista, Curitiba, Brasil, n. 50, p. 51-67, out./dez. 2013.

GATTI, B. A. Formação inicial de professores para a educação básica: pesquisas e políticas educacionais. Estudos em Avaliação Educacional, São Paulo, v. 25, n. 57, p. 24-54, jan./abr. 2014.

INSTITUTO BRASILEIRO DE GEOGRAFIA E ESTATÍSTICA - IBGE. Síntese de indicadores sociais: uma análise das condições de vida da população brasileira. Rio de Janeiro, 2013. Disponível em: <IBGE.http://biblioteca.ibge.gov.br/visualizacao/livros/liv88941.pdf>. Acesso em: 29 jun. 2016.

KUSSUDA, S. R. A escolha profissional de licenciados em Física de uma universidade pública. 2012. 184 f. Dissertação (mestrado) - Universidade Estadual Paulista, Faculdade de Ciências.

LEME, L. F. Atratividade do magistério para o ensino básico: estudo com ingressantes de cursos superiores da Universidade de São Paulo. 2012. 192 f. Dissertação (Mestrado em Educação) - Faculdade de Educação da Universidade de São Paulo, São Paulo.

LIBÂNEO, J. C. Antinomias na formação de professores e a busca de integração entre o conhecimento pedagógico-didático e o conhecimento disciplinar. In: MARIN, A. J.; PIMENTA, S. G. (Orgs.). Didática: teoria e pesquisa. Araraquara: Junqueira\&Marin, 2015, p. 39-65.

LISBOA, V. Quanto maior a escolaridade, maior a desigualdade de renda entre homem e mulher. Rio de janeiro: Agência Brasil, 2015. Disponível em: <http://agenciabrasilebc.com.br/ geral/noticia/2015-12/quanto-maior-escolaridade-maiordesigualdade-de-renda entre-homens-e-mulher>. Acesso em: 28 jun. 2016.

LOUZANO, P. et al. Quem quer ser professor? Atratividade, seleção e formação docente no Brasil. Estudos em Avaliação Educacional, São Paulo, v. 21, n. 47, p. 543-568, set./dez. 2010. Disponível

em: <http://www.fcc.org.br/pesquisa/publicacoes/eae/arquivos/1608/1608.pdf>. Acesso em: 29 de jun. 2016.

NOGUEIRA, C. M. M.; ALMEIDA, F. J.; QUEIROZ, K. A. S. A escolha da carreira docente: complexificando a abordagem sociológica. Vertentes, v. 19, n. 1, 2010. 
NUNES, C. M. F.; CUNHA, M. A. A. "Escrita de si” como estratégia de formação continuada para docentes. Revista Espaço Acadêmico, n. 50, jul. 2005. Disponível em: <http://www. espacoacademico.com.br/050/50pc_cunhan unes.htm>. Acesso em: 17 jan. 2016.

NUNES, C. P.; OLIVEIRA, D. A. Trabalho, carreira, desenvolvimento docente e mudança na prática educativa. Educação e Pesquisa, São Paulo, abr. 2016.

OBSERVATÓRIO DO PNE. Disponível em: < http://www.observatorio dopne.org.br/metaspne/15-formacao-professores $>$. Acesso em 26 out. 2017.

OLIVEIRA, A. C. et al. Você quer ser professor? E-xacta, Belo Horizonte, v. 4, n. 2 - Edição Especial Interdisciplinaridade. p. 37-42, 2011).

RABELO, R. P.; CAVENAGHI, S. M. Indicadores educacionais para formação de docentes: uso de dados longitudinais. Estudos em Avaliação Educacional, São Paulo, v. 27, n. 66, p. 816-850, set./dez. 2016.

ROZEK, M. A narrativa e a formação de professores. Indagatio Didactica, Rio Grande do Sul, v. 5, n. 2, out. 2013. Disponível em: <http://revistas.ua.pt/index.php/ID/article/view /2507/ 2373>. Acesso em: 02 jun. 2016.

SOUZA, E. C. (Auto) Biografia, histórias de vida e práticas de formação. In: NASCIMENTO, A. D.; HETKOWSKI, T. M. (Orgs). Memória e formação de professores. Salvador: EDUFBA, 2007.

TODOS PELA EDUCAÇÃO. Disponível em: <http://www.todospelaeducacao. org.br/reportagens-tpe/40805/menos-da-metade-dos-professores-dos-anos-finais-do-ensinofundamental-tem-licenciatura-para-todas-as-disciplinas-que-lecionam/>. Acesso em: 26 out. 2017.

VIEIRA, J. D. Valorização dos profissionais: carreira e salários. Revista Retratos da Escola, Brasília, v. 8, n. 15, p. 409-426, jul./dez. 2014. 